In this compact book the British reader is provided with an outline of the way in which the United States provides for its visually handicapped citizens. It could be the model for the publication here of a single volume which brought together and expanded information available now only under separate headings, frequently in the form of pamphlets. Even in its own setting there is not much available as competition for its particular place on the bookshelf. It is to be recommended as informative and stimulating reading.

Kryotherapie in der Augenheilkunde (Cryotherapy in Ocular Disease). By W. Matthäus and H. Krantz. I 973. P'p. 202, 55 figs, bibl. Steinkopff, Drusen. (DM 32)

This monograph was written by an ophthalmic surgeon and by an engineer. More than one-third of its pages are concerned with physical laws and data which apply to the production of low temperature and few ophthalmic surgeons will be interested in thermodynamics. The cryobiological effect on the tissues is clearly explained and, as regards the lens, the authors give pertinent advice on strength of the adhesion of the cryoprobe to the lens surface, the optimal temperature, and duration of the application. Gryoextraction seems to be the least dangerous method for removal of a lens which has been luxated into the vitreous. For retinal detachment the handling of a diathermy instrument appears to be easier than cryocautery. Other uses of cryotherapy relate to the treatment of corneal diseases, glaucoma, iridocyclitis, prolapse of the iris, and severing of vitreo-corneal adhesions. The book will appeal especially to an ophthalmic surgeon who is interested in physics. The authors stress that a perfect surgical technique is more important than an expensive apparatus.

\title{
Die Ophthalmo-Electromyographie. Zust Analyse der Augenmotäilittssforun-
} gen (Electromyography in Ophthalmology). By F. Sahulze. 1972. Pp. I92, 66 figs, bibl. Theime, Leipzig. (DM 55.20)

The book is an excellent guide to the technique and evaluation of electromyography. The method gives valuable information about the diagnosis, degree, and prognosis of various conditions, and the action of drugs can be ascertained in an objective way. The author should be given credit for stressing the difficulties and sources of error in electromyography. Repeated examinations are often required and the work of the laboratory technician has to be supplemented by that of the experienced clinician.

The Soft Contact Lens (Symposium and Workshop of the University of Florida, Gainesville). Edited by A. R. Gasset and H. E. Kaufman. 1972. Pp. 326, i 26 figs, I col. pl., bibl. Mosby, St. Louis; Kimpton, London. (£ I I.I5)

This book which contains the transactions of a symposium on soft lenses held in Gainesville, Florida, consists of several papers by scientists, optometrists, and ophthalmologists. They are chiefly concerned with the chemistry and physiology of the cornea under a lens, the types of lenses fitted, and the pathological ocular conditions treatable by these lenses. The materials and forms described are Bausch and Lomb (PolyHEMA), Biomite (PolyHEMA + P.V.P. Copolymer), and silicone rubber, and the advantages and disadvantages of each are discussed at some length. As always with a series of related papers, there is a considerable amount of unavoidable overlap. To the uninitiated the volume will provide a surfeit of opinion and valuable information, much of which has, however, changed since the meeting was held.

Augenheilkunde in Forschung und Praxis (Ocular Disease in Research and Practice). By K.-E. Kruger and M. Tost. 1972. Pp. 192, figs, bibl. Theime, Lcipzig. (DM 36)

This book contains short papers reviewing the progress made during the last few years in such fields as ophthalmological genetics, corneal surgery, and the orbit. Few ophthalmic surgeons will fail to 